\title{
FATIGUE LIFE OF ALUMINIUM ALLOY 6082 T6 UNDER CONSTANT AND VARIABLE AMPLITUDE BENDING WITH TORSION
}

\author{
Aleksander Karolczuk, Marta Kurek, Tadeusz Łagoda \\ Opole University of Technology, Faculty of Mechanical Engineering, Opole, Poland \\ e-mail: a.karolczuk@po.opole.pl; ma.kurek@po.opole.pl; t.lagoda@po.opole.pl
}

\begin{abstract}
The paper presents the comparison of experimental and calculated fatigue lives for EN AW-6082 T6 aluminium alloy. Hour-glass shaped specimens have been subjected to constant and variable amplitude uniaxial and multiaxial loadings, i.e. plane bending, torsion and their proportional combinations with zero mean values. Three multiaxial fatigue criteria based on the critical plane approach have been verified being the linear combination of shear and normal stresses on the critical plane. For the variable-amplitude loading, the rainflow cycle counting method and Palmgren-Miner hypothesis have been applied. The best fatigue criteria are pointed in the final conclusions.
\end{abstract}

Keywords: variable amplitude loading, multiaxial fatigue, aluminium alloy, critical plane approach

\section{Introduction}

Numerous components of machines and devices work under variable operational loadings that may damage the component and interrupt the work process. The phenomenon of fatigue of materials and structures is a significant issue in many sectors of the industry. One of the research objectives on material fatigue is to identify a proper method of estimating the fatigue strength and life on the stage of design of structural elements. Literature of the subject offers numerous reports whose authors (Carpinteri and Spagnoli, 2001; Kardas et al., 2008; Karolczuk and Kluger, 2014; Karolczuk and Macha, 2005; Karolczuk et al., 2008, Kluger and Łagoda, 2013; Łagoda and Ogonowski, 2005; Niesłony et al., 2014; Skibicki and Pejkowski, 2012; Walat et al., 2012; Walat and Lagoda, 2014) reviewed and verified multiaxial fatigue criteria. Among many multiaxial fatigue criteria, one group that is based on the determination of an equivalent stress in the critical plane can be distinguished as the group of increasing popularity. The popularity comes from a wide range of applicability and effectivenessof this approach. However, the critical plane approach still requires experimental validation. The main idea of the critical plane approach is reducing the multiaxial state of stress to the uniaxial (called equivalent) stress state by an appropriate fatigue hypothesis and critical plane orientation. The orientation of the critical plane and the location of fatigue failure plane are relative to the type of material used and loading conditions (Carpinteri et al., 2002; Walat and Łagoda, 2010).

The main aim of this paper is verification of three multiaxial fatigue criteria based on the critical plane approach under multiaxial constant and variable-amplitude loadings of aluminium alloy EN AW-6082 T6 (PN-PA4).

\section{Experimental research}

The analysis has been conducted using the results of experimental studies under constant- and variable-amplitude loading of EN AW-6082 T6 aluminium alloy. The chemical composition of 
the alloy is provided in Table 1. Basic mechanical parameters of the analysed material are listed in Table 2. Cyclic properties of the analysed material are provided in Table 3.

Table 1. Chemical composition of EN AW-6082 [in weight \%, EN 573-3: 2009] (the rest Al)

\begin{tabular}{|c|c|c|c|c|c|c|c|}
\hline $\mathrm{Cu}$ & $\mathrm{Mg}$ & $\mathrm{Mn}$ & $\mathrm{Si}$ & $\mathrm{Fe}$ & $\mathrm{Zr}+\mathrm{Ti}$ & $\mathrm{Zn}$ & $\mathrm{Cr}$ \\
\hline \hline$<0.1$ & $0.6-1.2$ & $0.4-1.0$ & $0.7-1.3$ & $<0.5$ & $<0.1$ & $<0.2$ & $<0.25$ \\
\hline
\end{tabular}

Table 2. Basic mechanical parameters of EN AW-6082 aluminium alloy

\begin{tabular}{|c|c|c|c|c|}
\hline$R_{p 0.2}[\mathrm{MPa}]$ & $R_{m}[\mathrm{MPa}]$ & $A_{12.5}[\%]$ & $E[\mathrm{GPa}]$ & $\nu[-]$ \\
\hline \hline 365 & 385 & 27.2 & 77 & 0.32 \\
\hline
\end{tabular}

Table 3. Cyclic properties of EN AW-6082 aluminium alloy

\begin{tabular}{|c|c|c|c|c|c|c|c|c|c|c|c|}
\hline \multicolumn{6}{|c|}{ Tension-compression } & \multirow{2}{*}{\multicolumn{3}{|c|}{$\frac{\text { Plane bending }}{\log N_{f}=C_{\sigma}}$}} & \multirow{2}{*}{\multicolumn{3}{|c|}{$\begin{array}{c}\text { Torsion } \\
\log N_{f}=C_{\tau}\end{array}$}} \\
\hline$\varepsilon_{a}^{p}=(c$ & $\left./ K^{\prime}\right)^{1 / n}$ & $\varepsilon_{a}=$ & $\overline{\left.\sigma_{f}^{\prime} / E\right)}$ & $\left.2 N_{f}\right)^{b}+$ & ${ }_{f}\left(2 N_{f}\right)^{c}$ & & & & & & \\
\hline $\begin{array}{c}K^{\prime} \\
{[\mathrm{MPa}]}\end{array}$ & $\begin{array}{l}n^{\prime} \\
{[-]}\end{array}$ & $\begin{array}{c}\sigma_{f}^{\prime} \\
{[\mathrm{MPa}]}\end{array}$ & $\begin{array}{l}\varepsilon_{f}^{\prime} \\
{[-]}\end{array}$ & $\begin{array}{c}b \\
{[-]}\end{array}$ & $\begin{array}{c}c \\
{[-]}\end{array}$ & $A_{\sigma}$ & $m_{\sigma}$ & $\sigma_{a f}$ & $A_{\tau}$ & $m_{\tau}$ & $\tau_{a f}$ \\
\hline 526 & 0.0651 & 651 & 1.292 & -0.0785 & -1.0139 & 23.8 & 8.0 & 154 & 21.4 & 7.7 & 91 \\
\hline
\end{tabular}

where: $\varepsilon_{a}^{p}$ - amplitude of plastic strain; $\varepsilon_{a}$ - total strain amplitude; $\sigma_{a}, \tau_{a}$ - stress amplitudes; $N_{f}$ - number of cycles to failure; $\sigma_{a f}=\sigma_{a}\left(2 \cdot 10^{6}\right), \tau_{a f}=\tau_{a}\left(2 \cdot 10^{6}\right)$ - theoretical fatigue limits $C_{\sigma}=A_{\sigma}-m_{\sigma} \log \sigma_{a}, C_{\tau}=A_{\tau}-m_{\tau} \log \tau_{a}$

(a)

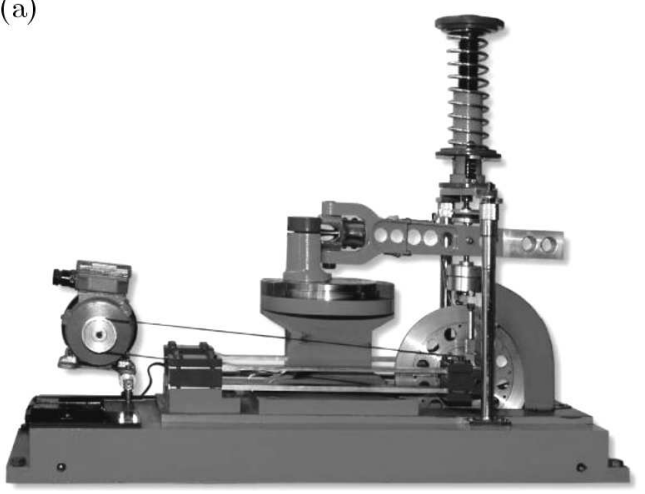

(b)

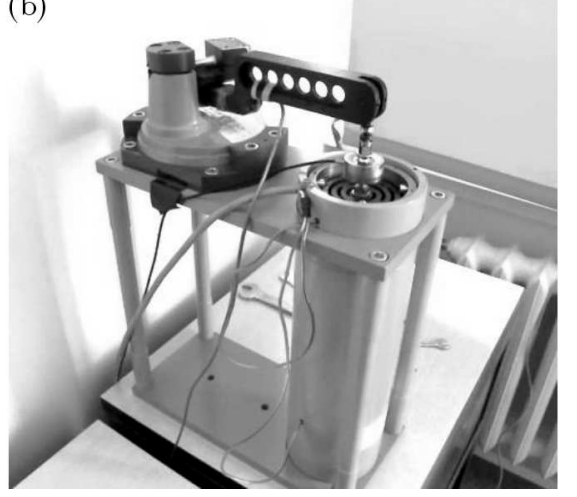

Fig. 1. Fatigue life test stands: (a) cyclic loading, (b) variable-amplitude loading

Tests under constant-amplitude loadings have been performed using MZGS-100 fatigue test stand (Achtelik and Jamroz, 1982), in which the electric engine drives the wheel, whose centre of mass is shifted with respect to axis of rotation (Fig. 1a). The frequency of loading was equal to $28 \mathrm{~Hz}$. The fatigue failure condition of specimen is increased of vibration amplitude by around $30 \%$. Tests under variable-amplitude loadings were performed on a prototype test stand, in which the force was induced by an electromagnetic actuator (Fig. 1b). In this case, the failure definition is total separation of specimen. The frequency of loading depending on the loading level) was in the range $5-10 \mathrm{~Hz}$.

The tests were performed on smooth specimens of circular cross section with hour-glass shape, as illustrated in Fig. 2.

In the case of the analysed constant- and variable amplitude loading, the samples were subjected to: (i) plane bending, (ii) plane bending with torsion and (iii) torsion. The results of fatigue tests of constant-amplitude bending and torsion are illustrated in the $\mathrm{S}-\mathrm{N}$ diagram in a log-log scale plot (Fig. 3), according to ASTM (ASTM, 1999). 


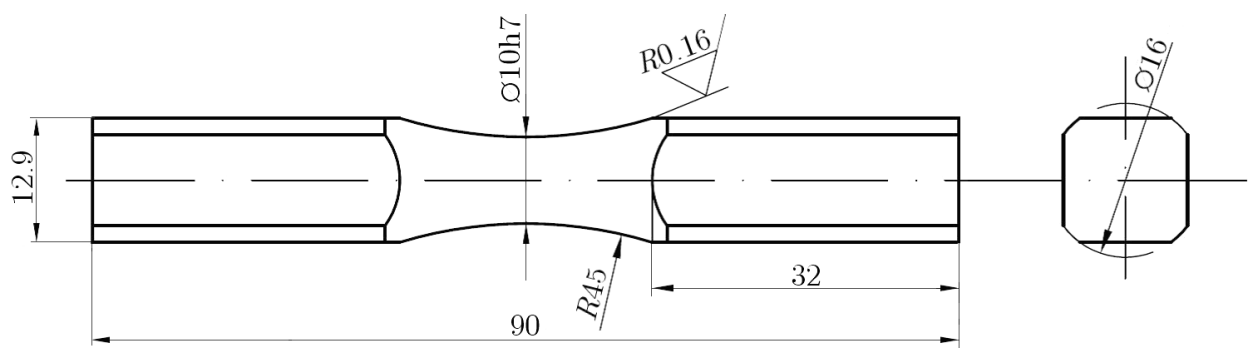

Fig. 2. Geometry of the tested specimen

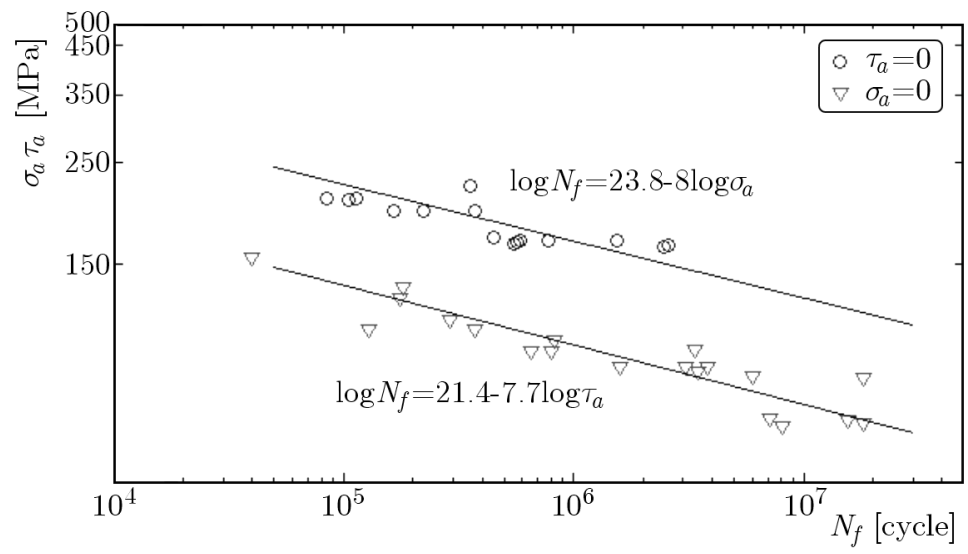

Fig. 3. Fatigue diagram for constant amplitude plane bending and torsion of aluminium alloy 6082 T6 (where $\tau_{a}$ and $\sigma_{a}$ denote stress amplitudes of torsion and bending moments, respectively)

The results show that the bending and torsion S-N curves are nearly parallel $\left(m_{\sigma}=8.0 \approx\right.$ $\left.m_{\tau}=7.7\right)$. In the case of analysis under variable-amplitude loading, the driving signal is a sinusoidal wave of variable amplitude. The control system randomly generated amplitudes of the driving force on the basis of the Rayleigh distribution. However, due to limited capacity of the test stand, the actual operational distribution differs from the generated one (Fig. 4c). Figure 4 illustrates the specific loading characteristics of the given loading level, i.e.: (a) recorded force $F$; (b) force $F$ in the time range of $10 \mathrm{~s}<t<15 \mathrm{~s}$; (c) histogram of amplitudes of the force $F$; (d) standard deviation $F_{a, s t d}$ of force amplitudes. The parameters of variable amplitude loadings recalculated to parameters of nominal stresses on the assumption of the elastic strain range are presented in Table 4.

Table 4. Parameters of variable amplitude loadings

\begin{tabular}{|l|c|c|c|c|c|c|c|c|}
\hline & $\lambda$ & No. & $\begin{array}{c}\sigma_{a, m} \\
{[\mathrm{MPa}]}\end{array}$ & $\begin{array}{c}\tau_{a, m} \\
{[\mathrm{MPa}]}\end{array}$ & $\begin{array}{c}\sigma_{a, s t d} \\
{[\mathrm{MPa}]}\end{array}$ & $\begin{array}{c}\tau_{a, s t d} \\
{[\mathrm{MPa}]}\end{array}$ & $\begin{array}{c}\sigma_{a, \max } \\
{[\mathrm{MPa}]}\end{array}$ & $\begin{array}{c}\tau_{a, \max } \\
{[\mathrm{MPa}]}\end{array}$ \\
\hline \hline Bending & 0 & 12 & $129-202$ & - & $55-73$ & - & $264-330$ & - \\
\hline Torsion & $\infty$ & 13 & - & $68-104$ & - & $30-42$ & - & $198-139$ \\
\hline Bending-torsion & 0.25 & 12 & $110-160$ & $27-39$ & $51-66$ & $12-16$ & $303-357$ & $74-87$ \\
\hline Bending-torsion & 0.50 & 12 & $85-124$ & $42-62$ & $38-52$ & $19-26$ & $248-262$ & $124-131$ \\
\hline Bending-torsion & 1.00 & 12 & $53-75$ & $54-76$ & $24-30$ & $25-31$ & $128-150$ & $131-154$ \\
\hline
\end{tabular}

The table contains five cases of loading described by: $\lambda=\tau_{a, m} / \sigma_{a, m}$ - ratio of mean values of stress amplitudes; No. - number of specimens; $\sigma_{a, m}, \tau_{a, m}$ - mean values of stress amplitudes for bending and torsion loadings, respectively; $\sigma_{a, s t d}, \tau_{a, s t d}$ - standard deviation of stress amplitudes for bending and torsion loadings, respectively; $\sigma_{a, \max }, \tau_{a, \max }-$ maximum values of stress amplitudes for bending and torsion loadings, respectively. Exemplary photos of the fracture surface are shown in Fig. 5. 


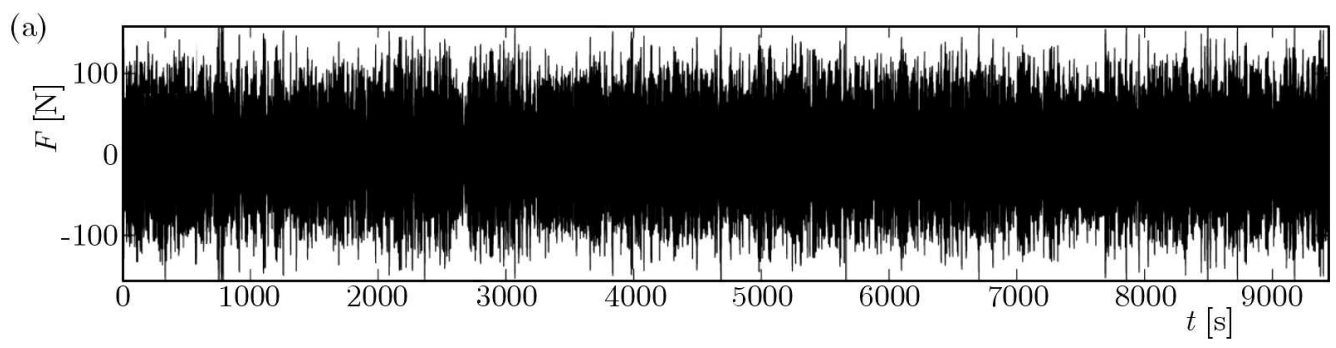

(b)

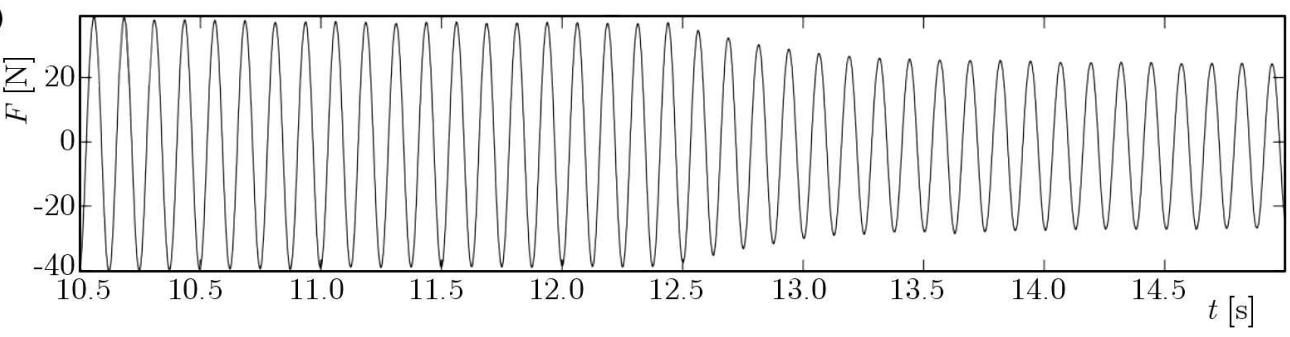

(c)
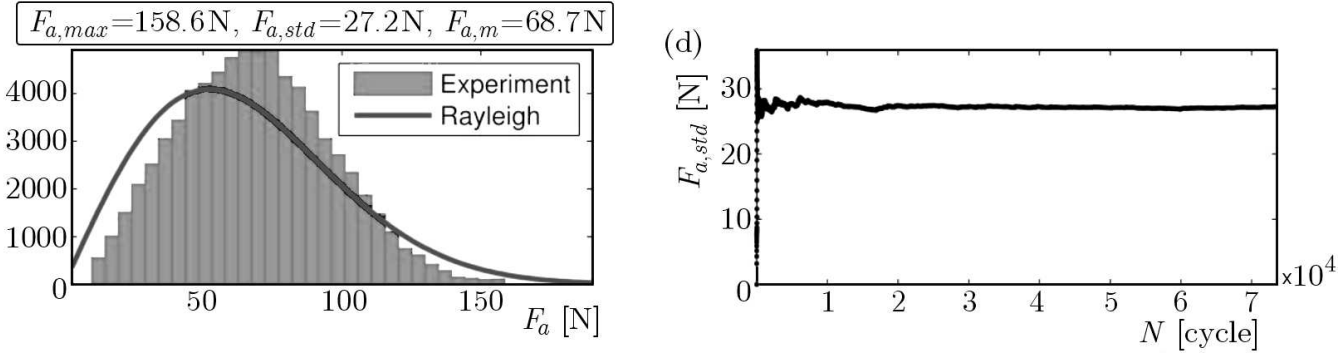

Fig. 4. Example of loading characteristics of plane bending: (a) recorded force $F(t)$; (b) force $F(t)$ in the time range of $10 \mathrm{~s}<t<15 \mathrm{~s}$; (c) histogram of amplitudes of the force $F$ with selected statistical parameters; (d) changes in the standard deviation of force amplitudes
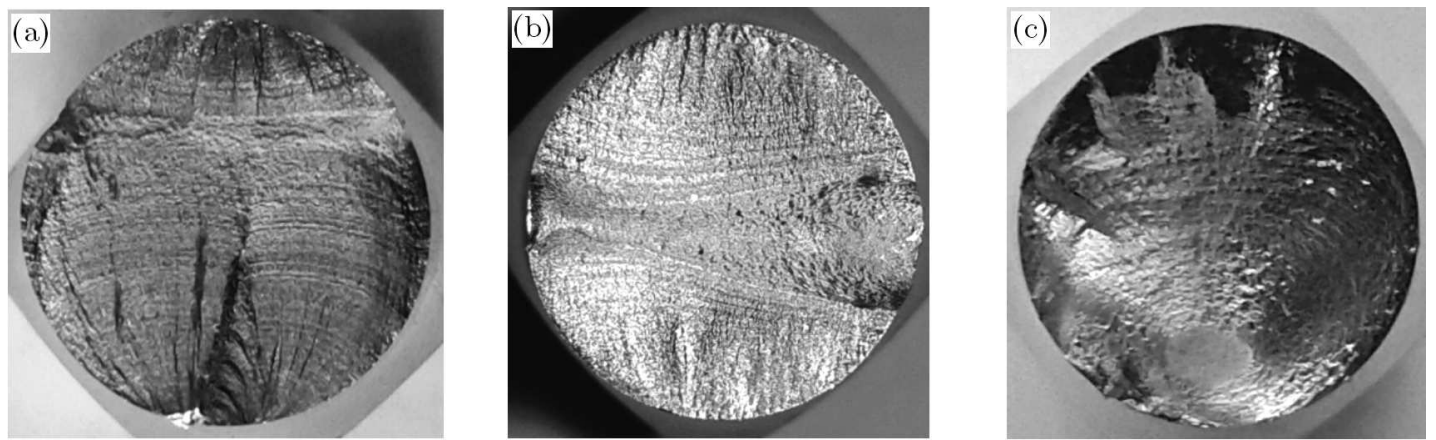

Fig. 5. Example of the fracture surface: (a) plane bending; (b) bending-torsion, $\lambda=0.25$;

(c) bending-torsion, $\lambda=1.0$

\section{The algorithm of fatigue life evaluation}

Figure 6 illustrates the scheme for estimating the fatigue life used in the calculations. The first block refers to calculating components of stress for the high cyclic fatigue regime (HCF) (elastic strain range). The next step involves determination of the critical plane orientation on which all the stress tensor components are transformed. The specified critical plane orientation depends on the selected fatigue criterion.

Calculations have been done (step 3) using three multiaxial fatigue criteria, based on the critical plane concept. The coefficients in the formulas for equivalent stress are calculated according 


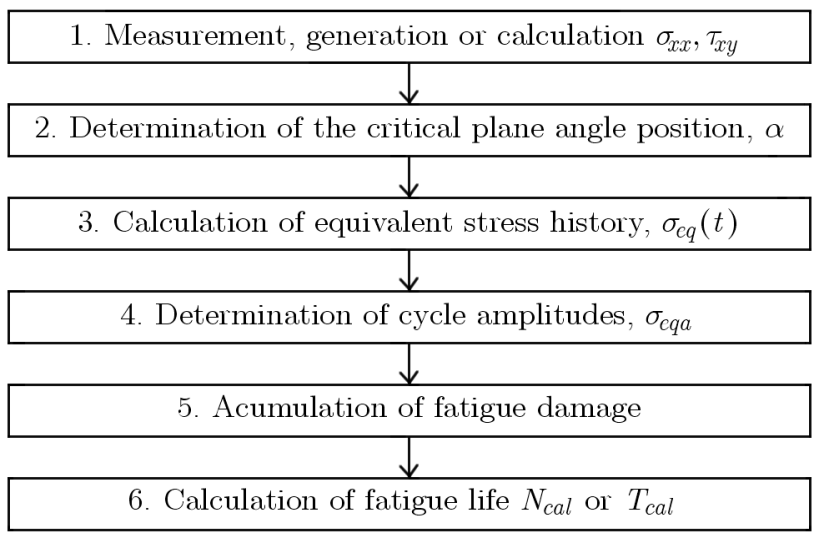

Fig. 6. The scheme of fatigue life calculation

to typical fatigue limits. The general form of the equivalent stress according to the criteria on the critical plane is expressed as

$$
\sigma_{e q}(t)=B \tau_{\eta s}(t)+K \sigma_{\eta}(t)
$$

where $B, K$ are constants used for selection of specific form of the equivalent stress (Eagoda and Ogonowski, 2005), $\sigma_{\eta}(t), \tau_{\eta s}(t)$ are, respectively, the normal and shear stresses in the selected plane.

Depending on the plane orientation, the following are applied in the study:

$\mathrm{C} 1$ - criterion in the maximum normal stress plane, for which B is the constant dependent on the material type, and $K=1$;

$\mathrm{C} 2$ - criterion in the maximum shear stress plane, for which B is the ratio of fatigue limits for bending and torsion limits $\sigma_{a f} / \tau_{a f}$, and $K=2-B$;

C3 - criterion in the plane rotated in respect to direction of maximum normal stress proposed by Carpinteri and Spagnoli (2001), for which

$$
B=\frac{1}{\sin 2 \beta}\left[\frac{\sigma_{a f}}{\tau_{a f}}(1+\cos 2 \beta)-2 \cos 2 \beta\right] \quad K=\frac{2+B \sin 2 \beta}{2 \cos ^{2} \beta}
$$

If the idea proposed by Carpinteri is used, the orientation of the critical plane will depend on the fatigue limits ratio and be inclined against the maximum normal stress plane by the angle

$$
\beta=\frac{3}{2}\left[1-\left(\frac{\tau_{a f}}{\sigma_{a f}}\right)^{2}\right] 45^{\circ}
$$

For the variable-amplitude loading, the next step involves calculation of cycles and half-cycles. This is done with the rainflow-counting algorithm developed by Dowling (1972). The fatigue damage degree is determined only for the variable-amplitude loading using the Palmgren-Miner linear damage hypothesis, according to which the degree of damage $S\left(T_{0}\right)$ over the observation time $T_{0}$ of the equivalent stress is calculated as follows

$$
S\left(T_{0}\right)=\left\{\begin{array}{lll}
\sum_{i=1}^{k} \frac{n_{i}}{N_{0}\left(\sigma_{a f} / \sigma_{e q a, i}\right)^{m_{\sigma}}} & \text { for } & \sigma_{\text {eqa }, i} \geqslant a \sigma_{a f} \\
0 & \text { for } & \sigma_{\text {eqa }, i}<a \sigma_{a f}
\end{array}\right.
$$

where $S\left(T_{0}\right)$ is the degree of damage of the material over time $T_{0}$ according to Palmgren-Miner hypothesis, $T_{0}$ - observation time, $k$ - number of class intervals of the amplitude histogram 
$(i<k), a$ - coefficient that allows including amplitudes below $\sigma_{a f}, N_{0}$ - number of cycles corresponding to the theoretical fatigue limit $\sigma_{a f}\left(N_{0}=2 \cdot 10^{6}\right), n_{i}$ - number of cycles with $\sigma_{e q a, i}$ equivalent stress amplitude (two identical half-cycles form one cycle, and one half-cycle equals half damage corresponding to the full cycle).

Following the determination of the degree of damage $S\left(T_{0}\right)$ according to formula (3.4), the next step for the algorithm is the calculation of the fatigue life

$$
T_{c a l}=\frac{T_{0}}{S\left(T_{0}\right)}
$$

In the case of cyclic loadings, the fatigue life is calculated using Basquin's law (Kurek and Łagoda, 2011; Kurek et al., 2014; Niesłony and Kurek, 2012; Niesłony et al., 2012) of fatigue, in accordance with the ASTM standard, expressed as

$$
N_{c a l}=10^{A_{\sigma}-m_{\sigma} \log \sigma_{e q a}}
$$

\section{Verification of the proposed criterion}

Figures 7-9 illustrate the comparison of the calculated and experimental number of cycles to failure with the use of the discussed method of calculation for constant-amplitude loadings. In the case of the criterion in maximum normal stress plane (C1) for proportional loading, $B$ may take any value, since the shear stress value is 0 .

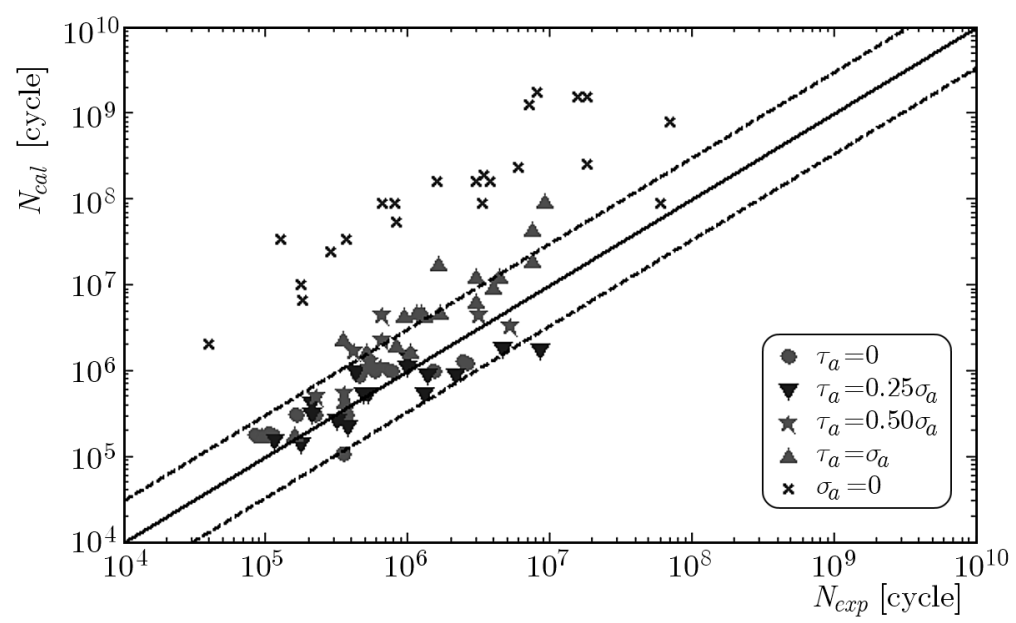

Fig. 7. Comparison of the calculated number of cycles with the experimental number of cycles to failure for aluminium alloy $6082 \mathrm{~T} 6$ under proportional loading, according to $\mathrm{C} 1$ criterion

Analysing the results of calculation and experimental tests (Figs. 7-9), it is determined that for the material in question, the highest conformity of results would be achieved by using the criterion in the maximum shear stress plane (C2 criterion) and the criterion C3. Figures 10-13 illustrate the comparison of obtained calculation strengths with experimental strengths for the variable-amplitude loading, calculated for different values of the coefficient $a$, using Palmgren-Miner hypothesis, for $a=0.5$ and $a=1$, respectively.

\section{Analysis of the obtained results}

In order to assess the analysed criteria, the procedure proposed in (Walat and Łagoda, 2014) has been applied, where the parameters of scatter between the experimental and calculation fatigue lives are calculated according to the following correlations 


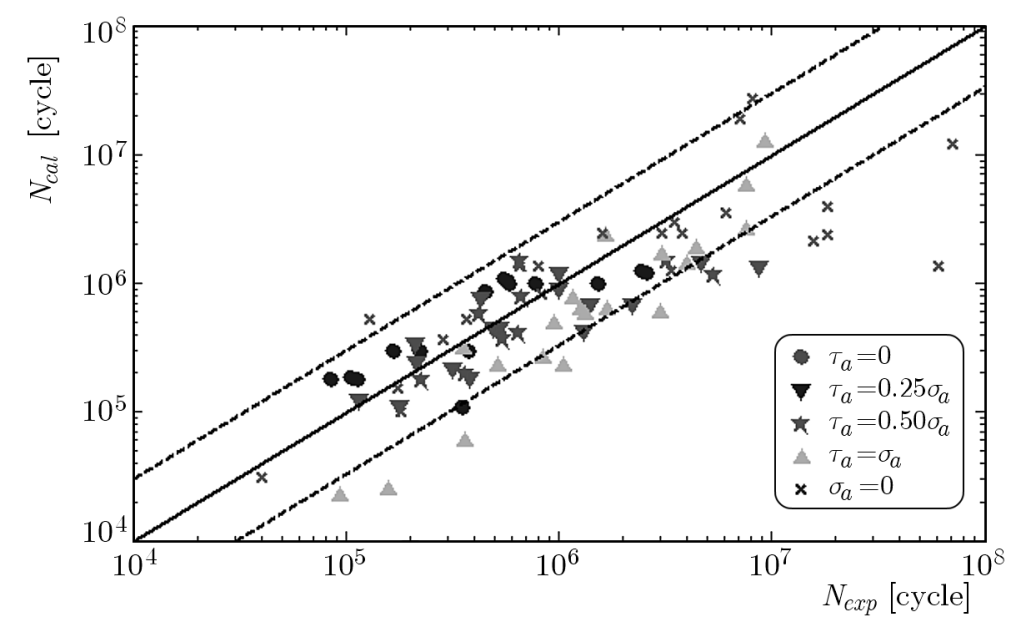

Fig. 8. Comparison of the calculated number of cycles with the experimental number of cycles to failurefor aluminium alloy $6082 \mathrm{~T} 6$ under proportional loading, according to $\mathrm{C} 2$ criterion

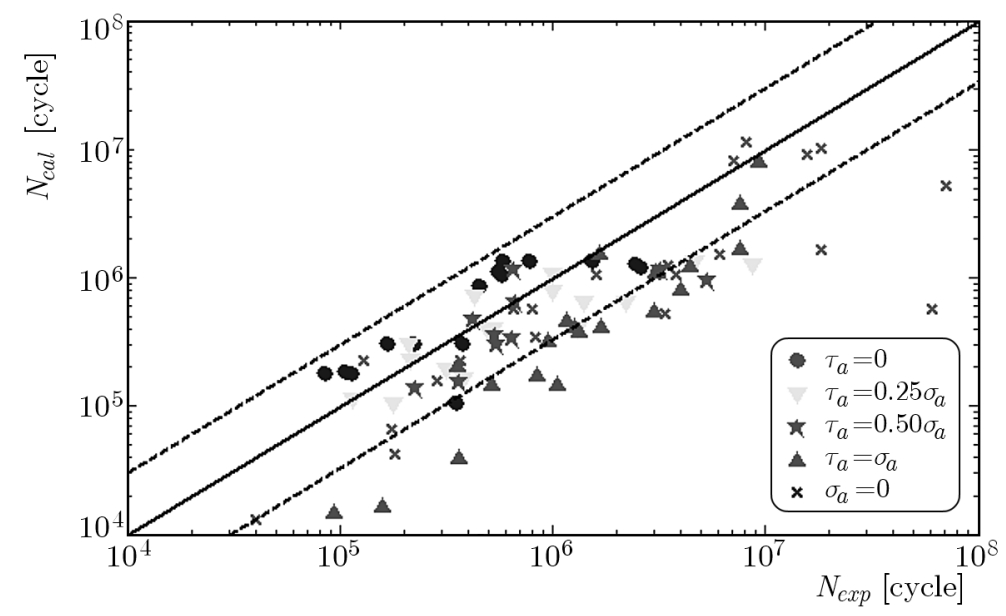

Fig. 9. Comparison of the calculated number of cycles with the experimental number of cycles to failure for aluminium alloy 6082 T6 under proportional loading, according to C3 criterion

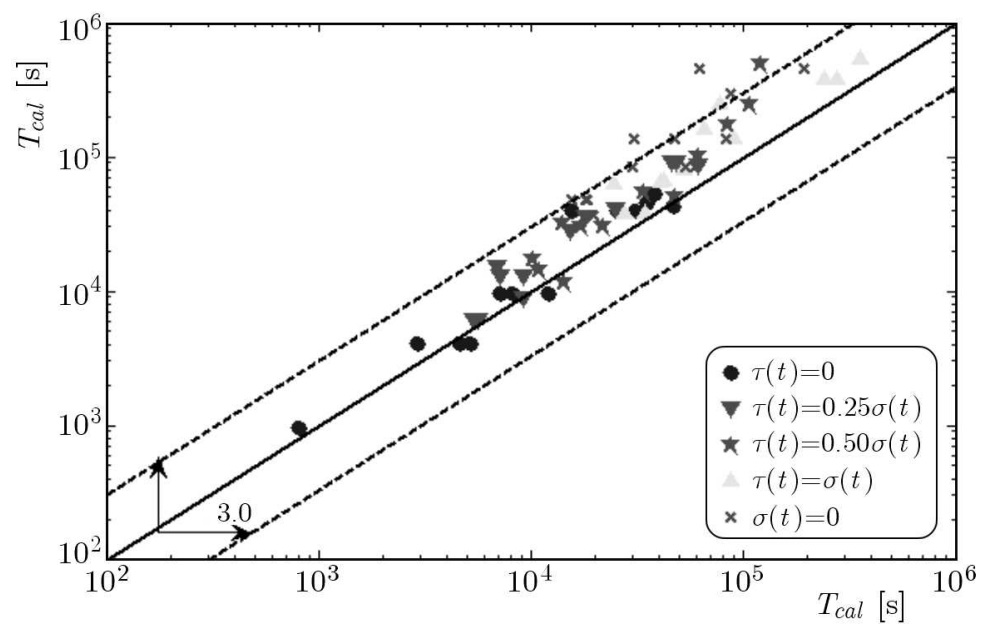

Fig. 10. Comparison of the calculated fatigue life with the experimental fatigue life for aluminium alloy 6082 T6 under random loadings, according to $\mathrm{C} 2$ criterion for $a=0.5$ 


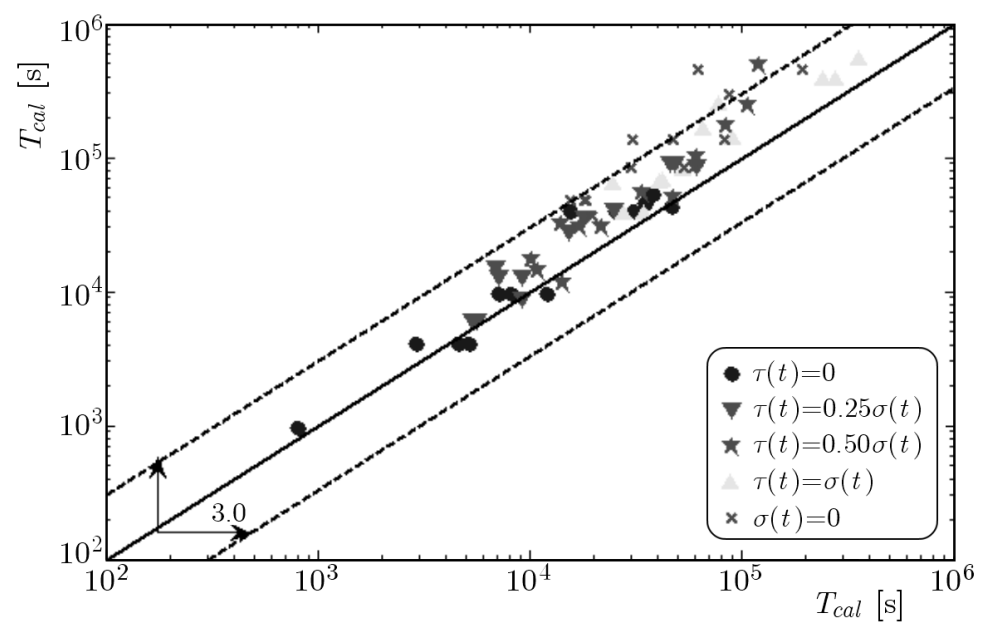

Fig. 11. Comparison of the calculated fatigue life with the experimental fatigue life for aluminium alloy 6082 T6 under random loadings, according to C2 criterion for $a=1$

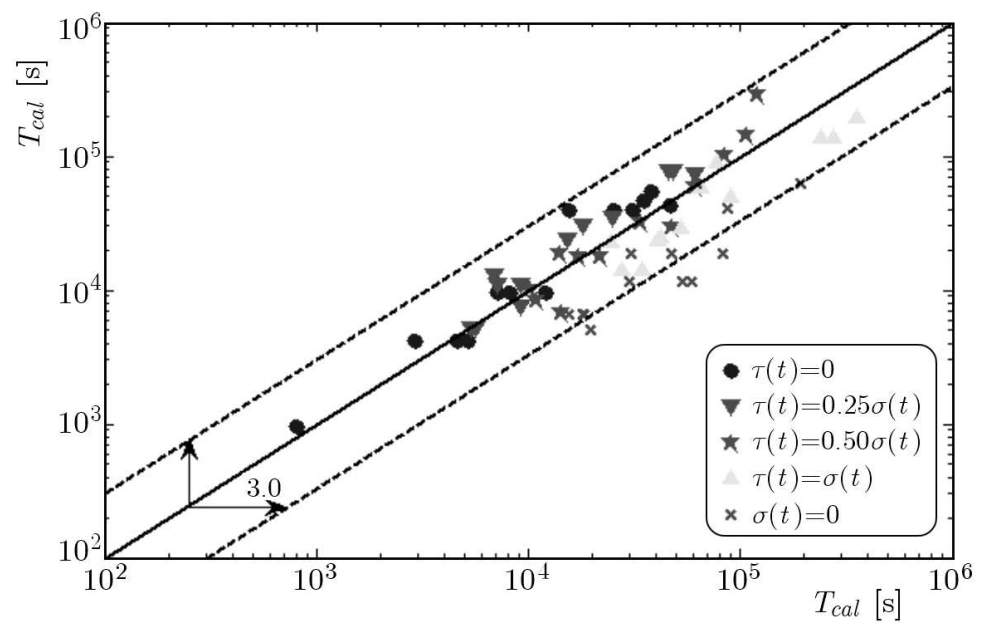

Fig. 12. Comparison of the calculated fatigue life with the experimental fatigue life for aluminium alloy 6082 T6 under random loadings, according to C3 criterion for $a=0.5$

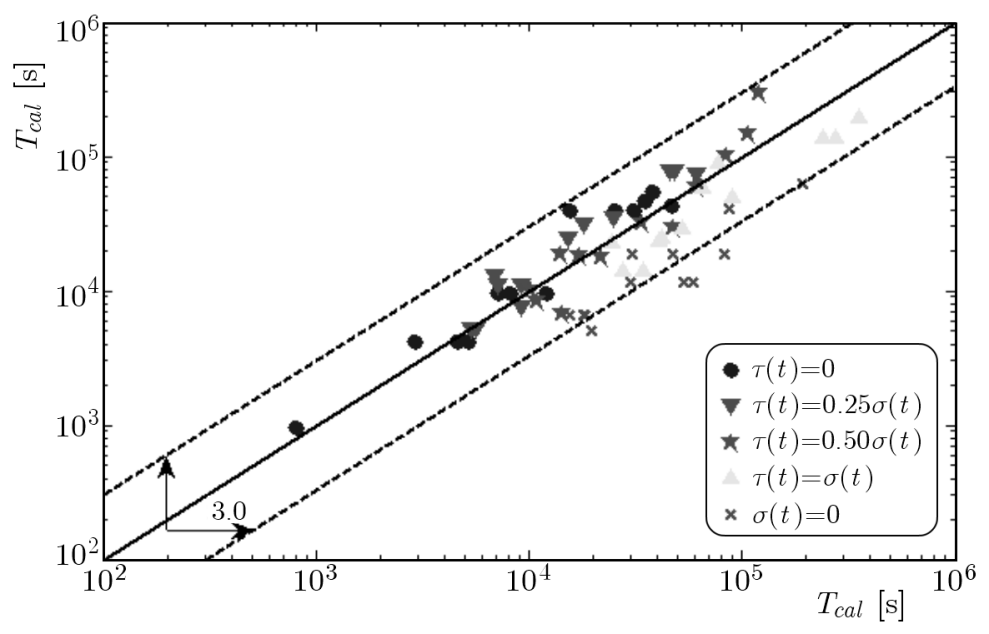

Fig. 13. Comparison of the calculated fatigue life with the experimental fatigue life for aluminium alloy 6082 T6 under random loadings, according to C3 criterion for $a=1$ 


$$
E=\sqrt{\frac{1}{n} \sum_{i=1}^{n} \log ^{2} \frac{N_{e x p}}{N_{c a l}}}
$$

where $n$ is the number of samples collected for analysis.

The final parameter for assessing the criterion is

$$
T=10^{E}
$$

Table 5 lists the results of calculations of the parameter $T$ for bending (experimental scatter with respect to the calculated characteristic (3.6)) and other forms of loading.

\begin{tabular}{|c|c|c|}
\hline & $\begin{array}{c}\text { Constant - } \\
\text { amplitude test }\end{array}$ & $\begin{array}{c}\text { Variable } \\
\text { amplitude test }\end{array}$ \\
\hline 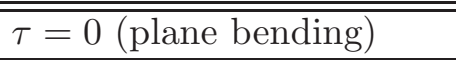 & 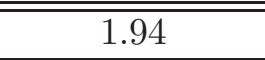 & 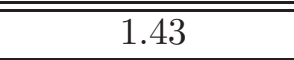 \\
\hline $\begin{array}{l}\text { Criterion in the maximum } \\
\text { normal stress plane }(\mathrm{C} 1)\end{array}$ & 9.67 & - \\
\hline \multirow{2}{*}{$\begin{array}{l}\text { Criterion in the maximum } \\
\text { shear stress plane }(\mathrm{C} 2)\end{array}$} & \multirow{2}{*}{2.67} & for $a=0.5 \quad 2.85$ \\
\hline & & for $a=1$ \\
\hline \multirow{2}{*}{$\begin{array}{l}\text { Modified criterion of } \\
\text { Carpinteri (C3) }\end{array}$} & \multirow{2}{*}{3.21} & for $a=0.5 \quad 2.63$ \\
\hline & & for $a=1$ \\
\hline
\end{tabular}

Table 5. Results of calculations of parameter T, Eq. (5.2), for fatigue life scatter

\section{Conclusions}

On the basis of analysis of the experimental tests and performed calculations, the following conclusions have been formulated:

- If the criterion in the maximum normal stress plane $(\mathrm{C} 1)$ is used, the calculated fatigue lives for aluminium alloy $6082 \mathrm{~T} 6$ will be incorrect.

- When the criterion in the maximum shear stress plane and the criterion (C3) are used, the calculated fatigue lives will approach the values of experimental ones for constant- and variable amplitude loadings. However, for both criteria, the determined scatter coefficient $T$ is higher than the scatter in the experimental tests. For the constant-amplitude loading, higher conformity has been obtained by using the criterion in the maximum shear stress plane $(\mathrm{C} 2)$, and for variable-amplitude loading the lowest scatter has been obtained by using the criterion $(\mathrm{C} 3)$.

- For different values of the coefficient $a$ in the Palmgren-Miner hypothesis, the results do not differ significantly. For coefficient $a=0.5$, slightly better calculation results have been obtained.

Project financed by the National Science Centre. Decision number: 2011/01/B/ST8/06850.

\section{References}

1. Achtelik H., Jamroz L., 1982, Patent PRL no 112497, CSR no 200236, HDR No. 136544

2. ASTM E 739-91, Standard practice for statistical analysis of linearized stress-life (S-N) and strain life (S-N) fatigue data, Philadelphia 1999 
3. Carpinteri A., Karolczuk A., Macha E., Vantadori S., 2002, Expected position of the fatigue fracture plane by using the weighted mean principal Euler angles, International Journal of Fracture, 115, 87-99

4. Carpinteri A., Spagnoli A., 2001, Multiaxial high-cycle fatigue criterion for hard metals, International Journal Fatigue, 23, 135-145

5. Dowling N.E., 1972, Fatigue failure prediction for complicated stress-strain histories, Journal of Materials, 7, 1, 71-87

6. Kardas D., Kluger K., Łagoda T., Ogonowski P., 2008, Fatigue life of aluminium alloy 2017(A) under proportional constant amplitude bending with torsion in energy approach, Materials Science, 4, 68-74

7. Karolczuk A., Kluger K., 2014, Analysis of the coefficient of normal stress effect in chosen multiaxial fatigue criteria, Theoretical and Applied Fracture Mechanics, 73, 39-47

8. Karolczuk A., Macha E., 2005, Critical planes in multiaxial fatigue, Materials Science Forum, 482, 109-114

9. Karolczuk A., Nadot Y., Dragon A., 2008, Non-local stress gradient approach for multiaxial fatigue of defective material, Computational Materials Science, 44, 464-475

10. Kluger K., EAgoda T., 2013, Fatigue life of metallic material estimated according to selected models and load conditions, Journal of Theoretical and Applied Mechanics, 51, 581-592

11. Kurek M., EAgoda T., 2011, Comparison of fatigue characteristics for some selected structural materials under bending and torsion, Materials Science, 47, 3, 334-344

12. Kurek M., Łagoda T., Katzy D., 2014, Comparison of fatigue characteristics of some selected materials, Materials Testing, 56, 92-95

13. Engoda T., Ogonowski P., 2005, Criteria of multiaxial random fatigue based on stress, strain and energy parameters of damage in the critical plane, Material wissenschaft und Werkstofftechnik, 36, 9, 429-437

14. NiesŁony A., KureK A., 2012, Influence of the selected fatigue characteristics of the material on calculated fatigue life under variable amplitude loading, Applied Mechanics and Materials, 104, 197-205

15. Niestony A., Kurek A., El Dsoki Ch., Kaufmann H., 2012, A study of compatibility between two classical fatigue curve models based on some selected structural materials, International Journal of Fatigue, 39, 88-94

16. NiesŁony A., Łagoda T., Walat K., Kurek M., 2014, Multiaxial fatigue behaviour of selected aluminium alloys under bending with torsion loading condition, Material wissenschaft und Werkstofftechnik, 45, 10, 947-952

17. Skibicki D., Pejkowski Ł., 2012, Integral fatigue criteria evaluation for life estimation under uniaxial combined proportional and non-proportional loadings, Materials Science Forum, 726, 189-192

18. Walat K., Kurek M., Ogonowski P., Eagoda T., 2012, The multiaxial random fatigue criteria based on strain and energy damage parameters on the critical plane for the low-cycle range, International Journal of Fatigue, 37, 100-111

19. Walat K., Łagoda T., 2010, Application of the covariance on the critical plane for determination of fatigue life under cyclic loading, Procedia Engineering, 2, 1211-1218

20. WALAT K., Łagoda T., 2014, Lifetime of semi-ductile materials through the critical plane approach, International Journal of Fatigue, 67, 73-77 